\title{
Screening and optimization of indole-3- acetic acid production by Rhizobium sp. strain using response surface methodology
}

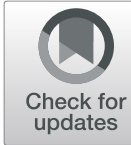

Sara Lebrazi ${ }^{1 *}$, Mouhcine Fadil ${ }^{2}$, Marwa Chraibi ${ }^{1}$ and Kawtar Fikri-Benbrahim ${ }^{1}$

\begin{abstract}
Background: The production of indole-3-acetic acid (IAA) is an essential tool for rhizobacteria to stimulate and facilitate plant growth. For this, eighty rhizobial bacteria isolated from root nodules of Acacia cyanophylla grown in different regions of Morocco were firstly screened for their ability to produce IAA. Then, IAA production by a combination of isolates and the inoculation effect on the germination of Acacia cyanophylla seeds was studied using the best performing isolates in terms of IAA production. The best IAA producer bacterial isolate (169) was selected to optimize IAA production using response surface methodology based on the central composite design.

Results: Results showed that the majority of tested isolates were able to produce IAA with a relatively higher concentration of $135 \mu \mathrm{g} / \mathrm{ml}$ for the isolate 169 , followed by isolates 122 and 175 with respective concentrations of $116 \mu \mathrm{g} / \mathrm{ml}$ and $105 \mu \mathrm{g} / \mathrm{ml} \mathrm{IAA}$. The IAA production and the seed germination rate were relatively increased by the synergistic effect of 169 and 122. Later, response surface methodology was used to determine optimal operating conditions leading to IAA production optimization. Thus, an incubation temperature of $36^{\circ} \mathrm{C}$, a pH of 6.5 , an incubation time of 1 day, and respective tryptophan and $\mathrm{NaCl}$ concentrations of $1 \mathrm{~g} / \mathrm{l}$ and $0.1 \mathrm{~g} / \mathrm{l}$ were optimal parameters leading to $166 \mu \mathrm{g} / \mathrm{ml}$ IAA which was the maximal produced concentration.
\end{abstract}

Conclusion: The present study highlighted that IAA-producing rhizobacteria could be harnessed to improve plant growth. Furthermore, their production can be easily controlled using response surface methodology, which represents a very useful tool for optimization.

Keywords: Rhizobium, Plant growth, Indole-3-acetic acid, Optimization, Experimental design, Response surface methodology

\section{Background}

Indole-3-Acetic Acid (IAA) is one of the most important and physiologically active phytohormones $[1,2]$. It is a secondary metabolite of L-tryptophan that acts as a regulator of many biological processes for plant development while acting on organogenesis, trophic responses, and cellular responses such as cell expansion, division, differentiation, and regulation of genes $[3,4]$. The majority of rhizobacteria can produce IAA that is the most

\footnotetext{
*Correspondence: s.lebrazi@gmail.com

'Laboratory of Microbial Biotechnology, Sciences and Technology Faculty, Sidi Mohamed Ben Abdellah University, P.O. Box 2202, Fez, Morocco Full list of author information is available at the end of the article
}

abundant type of auxins [5]. Under natural conditions, plant roots excrete organic compounds, including L-Trp that can be used by rhizobacteria for IAA biosynthesis which can help non-native plant species to resist under biotic and abiotic stress conditions [6-8]. However, little information is available on the relationship between stress and auxins in plants, and the evolutionary role played by auxin in adapting plants to various environmental stresses $[9,10]$.

Indeed, several authors have reported the role of this phytohormone in plants' adaptation to salinity stress [11, 12] and heavy metal stresses [13]. IAA has been well documented as an essential phytohormone known 
primarily for its ability to stimulate plant growth and development $[6,14]$. Indeed, IAA synthesized by rhizobacteria affects mostly the root system by increasing its size, weight, lateral roots number, and the area of contact with the soil. This mechanism contributes to increase nutrient research and acquisition in soil, which improves plant development and yield $[15,16]$. Moreover, IAA can act as a reciprocal signaling molecule by affecting gene expression in many bacteria and also plays a critical role in the plant-bacteria interaction $[17,18]$. Also, it has been shown that nodulated roots contain more IAA than non-nodulated roots $[19,20]$, and auxins could be essential for maintaining a root nodule functional [21].

IAA production by rhizobacteria can differ considerably between different species or strains of the same species. Moreover, several environmental factors can influence the biosynthesis of this phytohormone [22], in particular, a high $\mathrm{pH}$ and the presence of large quantities of tryptophan, which lead to an increase in its production [21]. In fact, Chandra et al. [23] found that their tested isolates for optimizing the IAA production showed better amount of IAA produced at $\mathrm{pH}$ 9. Similarly, Shoukry et al. [24] reported that $\mathrm{pH} 7$ was the optimum growth $\mathrm{pH}$ for IAA production by Rhizobium strains in medium supplemented with $5 \mathrm{~g} / \mathrm{l} \mathrm{L}$-tryptophan.

This study aimed to perform a screening of rhizobacteria that produce IAA and to optimize factors leading to the highest IAA concentration using experimental designs methodology. These methods allow experimentation with a minimum number of experiments and give the possibility of screening for different factors [25] from the most influential to the least influential. Also, it makes possible the optimization of the operating conditions giving the best possible result.

Several studies have addressed the topic of IAA production optimization. Some of them have used the classical optimization approach, which consists in studying the effect of each factor separately while fixing the others $[24,26,27]$. Others have used designs of experiments type Taguchi [28] and Plackett and Burman [29]. The use of experimental designs in optimization has shown many benefits compared to the classical approach because it gives the possibility of modeling responses and studying the interaction between factors. In this way, we have chosen to use a response surface design because it is better recommended than the Plackett and Burman designs and Taguchi tables since it concerns an optimization rather than a factor screening.

\section{Methods}

Isolation of rhizobia from nodules

Nodules were harvested, according to the method recommended by Vincent [30] and Beck et al. [31], from the roots of Acacia cyanophylla from three Moroccan regions (Eastern, Central, and North West). These nodules were immersed in $95 \%(\mathrm{v} / \mathrm{v})$ ethanol for $30 \mathrm{~s}$, then transferred to a mercury chloride $\left(\mathrm{HgCl}_{2}\right)$ solution $0.1 \%$ for $4 \mathrm{~min}$. A series of three rinses of 10, 15, and $20 \mathrm{~min}$, respectively, were performed under aseptic conditions using sterile distilled water [30, 32]. Surface-sterilized nodules were crushed using a few drops of $\mathrm{NaCl}(9 \%)$ [31]. The operation was performed under conditions of total asepsis. One hundred microliters of the suspension obtained was spread on Petri dishes containing YeastMannitol-Agar (YMA) medium [30].

\section{Screening of isolates for IAA production}

Different Rhizobium isolates from Acacia cyanophylla's root nodules isolated from three Moroccan regions (Eastern, Central, and North West) were tested for their ability to produce IAA. For this, the amount of IAA production in each isolate was determined by the colorimetric technique by using Salkowski reagent containing: $50 \mathrm{ml}, 35 \%$ perchloric acid $\left(\mathrm{HClO}_{4}\right) ; 1 \mathrm{ml}$ of $0.5 \mathrm{M}$ iron trichloride $\left(\mathrm{FeCl}_{3}\right)$ according to the protocol proposed by Bric et al. [33]. The bacterial isolates were cultured in Erlenmeyer of $250 \mathrm{ml}$ containing $50 \mathrm{ml}$ of YMB supplemented with $2 \mathrm{~g} / \mathrm{l}$ L-tryptophan, at $28 \pm 2{ }^{\circ} \mathrm{C}$ for 7 days at a shaking speed of $150 \mathrm{rpm}$ in an orbital shaking incubator. Afterward, bacterial cultures were centrifuged at $10.000 \mathrm{rpm}$ for $10 \mathrm{~min}$ at $4{ }^{\circ} \mathrm{C}$, and the supernatant liquid was mixed with Salkowski reagent (1:2). The mix was incubated for $30 \mathrm{~min}$ in the dark at $28 \pm 2{ }^{\circ} \mathrm{C}$, and then absorbance was measured at $530 \mathrm{~nm}$. The concentration of IAA produced was estimated using a standard IAA curve. All IAA determination experiments were made in triplicate.

\section{Study of IAA production by a combination of isolates}

The IAA production by a combination of the three best producing strains of this acid (Rhizobium sp. KX884 900.2 (I22), Rhizobium sp. KJ748400.1 (I69), and Agrobacterium rhizogenes CP019702.1 (I75) was tested. For this, from the primary cultures of the three bacterial strains $\left(10^{8} \mathrm{CFU} / \mathrm{ml}\right)$, four mixed cultures $(\mathrm{I} 22+\mathrm{I} 69$, I22 $+\mathrm{I} 75, \mathrm{I} 69+\mathrm{I} 75$, and I22 + I69 + I75) were prepared and then tested in $50 \mathrm{ml}$ of YMB medium supplemented with L-tryptophan $(1 \mathrm{~g} / \mathrm{l})$. After incubation at $28 \pm 2{ }^{\circ} \mathrm{C}$ with $150 \mathrm{rpm}$ for 7 days, cultures were centrifuged, and the IAA concentration produced was measured and estimated for each culture at $530 \mathrm{~nm}$ using the Salkowski reagent. Three repetitions were made for each test.

\section{Effect of inoculation on A. cyanophylla seed germination Seed preparation}

Tested seeds were obtained from the High Commission for Water and Forests and the Fight against Desertification of Fes-Boulemane region (http://www.eauxetforets. gov.ma). Then, they were surface-sterilized with $70 \%$ 
ethanol $(\mathrm{v} / \mathrm{v})$ and immersed in $0.1 \%(\mathrm{w} / \mathrm{v})$ fresh-made $\mathrm{HgCl}_{2}$ for $5-10 \mathrm{~min}$, followed by three washes with sterile distilled water and soaking in $95 \% \mathrm{H}_{2} \mathrm{SO}_{4}$ to scarify them $[34,35]$. After rinsing with sterile distilled water, seeds were imbibed under sterile conditions for $6 \mathrm{~h}$ at room temperature.

\section{Preparation of the bacterial inoculum and seed bacterization}

The three Rhizobium isolates, showing the highest IAA productions, were selected to verify their effect on the germination of $A$. cyanophylla's seeds. These isolates were cultured separately in liquid stirred YMB $(150 \mathrm{rpm})$ at $28{ }^{\circ} \mathrm{C}$ for $48 \mathrm{~h}$. Then, the bacterial suspensions were centrifuged at $10,000 \mathrm{rpm}$ for $10 \mathrm{~min}$. The pellet was suspended in $10 \mathrm{ml}$ of $\mathrm{MgSO}_{4}, 7 \mathrm{H}_{2} \mathrm{O}(0.1 \mathrm{M})$, and surface-sterilized seeds were soaked in the bacterial suspension for $30 \mathrm{~min}$. The control seeds were immersed in a magnesium sulfate solution for the same duration [36]. Seeds were subsequently dried in a stream of sterile air for $1 \mathrm{~h}$ [37]. Germination was performed in Petri dishes containing $1 \%$ agar and incubated in the dark at $28^{\circ} \mathrm{C}$ until radicle emergence for 3 to 10 days. The parameters studied in this test are root length and final germination rate, which is expressed as the ratio of the germinated seed number on total seed number.

\section{Experimental design}

Experimental designs present useful tools for parameters' screening and optimization. Based on the laws of statistical regression, they allow the quantification of various factor effects on a studied response and the optimization of operating conditions in well-defined experimental areas.

The central composite design, which is a part of response surface methodology, is used for response optimization. In this context, a sequence of experiments is carried out to evaluate the effect of factors on response and to obtain the optimal response.

\section{The fitted model}

To express the response as a function of the independent variables, we have used a quadratic model such as Eq. (1):

$$
\begin{aligned}
\mathrm{Y}= & \mathrm{b}_{0}+\mathrm{b}_{1} \mathrm{X}_{1}+\mathrm{b}_{2} \mathrm{X}_{2}+\mathrm{b}_{3} \mathrm{X}_{3}+\mathrm{b}_{4} \mathrm{X}_{4}+\mathrm{b}_{5} \mathrm{X}_{5} \\
& +\mathrm{b}_{11} \mathrm{X}_{1} \mathrm{X}_{1}+\mathrm{b}_{22} \mathrm{X}_{2} \mathrm{X}_{2}+\mathrm{b}_{33} \mathrm{X}_{3} \mathrm{X}_{3} \\
& +\mathrm{b}_{44} \mathrm{X}_{4} \mathrm{X}_{4}+\mathrm{b}_{55} \mathrm{X}_{5} \mathrm{X}_{5}+\mathrm{b}_{12} \mathrm{X}_{1} \mathrm{X}_{2} \\
& +\mathrm{b}_{13} \mathrm{X}_{1} \mathrm{X}_{3}+\mathrm{b}_{23} \mathrm{X}_{2} \mathrm{X}_{3}+\mathrm{b}_{14} \mathrm{X}_{1} \mathrm{X}_{4} \\
& +\mathrm{b}_{24} \mathrm{X}_{2} \mathrm{X}_{4}+\mathrm{b}_{34} \mathrm{X}_{3} \mathrm{X}_{4}+\mathrm{b}_{15} \mathrm{X}_{1} \mathrm{X}_{5} \\
& +\mathrm{b}_{25} \mathrm{X}_{2} \mathrm{X}_{5}+\mathrm{b}_{35} \mathrm{X}_{3} \mathrm{X}_{5}+\mathrm{b}_{45} \mathrm{X}_{4} \mathrm{X}_{5}+\varepsilon
\end{aligned}
$$

with $\mathrm{Y}=$ the response (IAA) expressed in $(\mu \mathrm{g} / \mathrm{ml}) ; \mathrm{b}_{0}$ is the constant term; $b_{1}, b_{2} b_{3} b_{4} b_{5}$ are coefficients of the main terms; $b_{11}, b_{22}, b_{33}, b_{44}$, and $b_{55}$ are coefficients of quadratic terms; and $b_{12}, b_{13}, b_{23} ; b_{14}, b_{24}, b_{34}, b_{15}, b_{25}$, $b_{35}$ and $b_{45}$ are coefficients of binary terms

\section{Statistical analysis}

The second-order model coefficients were calculated based on the experimental data. The statistical analysis was carried out using ANOVA test. In this way, the ratio between the mean square regression (MSR) and the mean square residual (MSr), $F_{\text {ratio(R/r) }}$, was used at a $95 \%$ significance level to check the model statistical significance [38].

\section{Optimization of IAA production by experimental design} Among all tested isolates, the best IAA producer was selected to study the effect of different variables on this phytohormone's production. Later, its optimization based on response surface methodology-central composite design was investigated. The chosen variables were Ltryptophan and $\mathrm{NaCl}$ concentrations, $\mathrm{pH}$, incubation time, and incubation temperature. All factors were studied at three different levels (Table 1).

\section{Results}

\section{Screening of isolates for IAA production}

The colorimetric assay showed that $96 \%$ of the eighty tested isolates were able to produce IAA on YMB medium at varying concentrations depending on their efficiency and their enzymatic potency. Indeed, a relatively higher concentration was found in the culture filtrate of strain I69 $(135 \mu \mathrm{g} / \mathrm{ml})$.

\section{Study of IAA production by a combination of isolates}

The combined effect of the three best IAA producers (I22, I69, and I75) was studied.

The obtained results revealed that the combination of two isolates I22 and I69 induces the highest hormonal production with $158.68 \mu \mathrm{g} / \mathrm{ml}$ of IAA (Fig. 1). However, the inoculation by 175 , in combination with the other two isolates, showed a negative effect on IAA production.

Table 1 Factors and their levels used in the optimization of IAA production by Rhizobium sp. using the central composite design

\begin{tabular}{lllll}
\hline Symbol & Variables & Level 1 & Level 2 & Level 3 \\
\hline $\mathbf{X 1}$ & {$[$ L-tryptophan] $(\mathrm{g} / \mathrm{l})$} & 0.1 & 0.5 & 0.9 \\
$\mathbf{X 2}$ & {$[\mathrm{NaCl}](\mathrm{g} / \mathrm{l})$} & 0 & 2.5 & 5 \\
$\mathbf{X 3}$ & Temperature $\left({ }^{\circ} \mathrm{C}\right)$ & 30 & 36 & 42 \\
$\mathbf{X}$ 4 & $\mathrm{pH}$ & 4 & 6.5 & 9 \\
$\mathbf{X 5}$ & Incubation time (days) & 1 & 8 & 15 \\
\hline
\end{tabular}




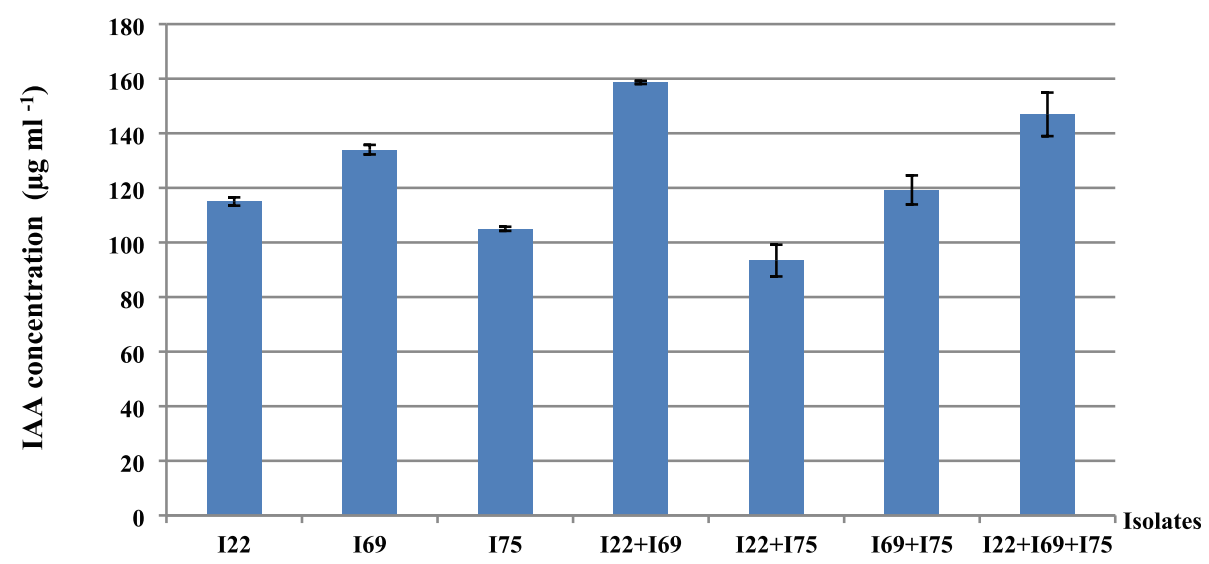

Fig. 1 Production of IAA by the combination of three rhizobial isolates (I22, 169, and 175)

Inoculation effect on Acacia cyanophylla seed germination The two isolates I22 and I69 having the ability of synergistic IAA biosynthesis were further tested for their impact on seed germination of A. cyanophylla and seedling growth. The observations were made under controlled conditions in Petri dishes, where the effect of the tested bacteria on the plant's growth is a direct consequence of its interaction with the plant. Seed bacterization by both of the studied isolates (Fig. 2) showed their ability to form a beneficial association with the A. cyanophylla seedlings. Isolates I22 and I69 were able to increase the germination rate by 1.61 and 1.68 times, respectively, compared to control, while the submission of seeds to a combination of these two isolates showed a germination rate increase of 1.87 times. Thus, stimulation of stem length and seedling roots has been demonstrated by our isolates. Respective increases of stem length of $1.62,1.75$, and 2 times were observed for inoculation treatments with I22, I69, and I22 + I69, while root length increases of 2.72, 3.09, and 3.63 times were respectively obtained for the three inoculation treatments. The results obtained during this study showed a significant effect of isolates on seedling germination and growth $(p<0.001)$.

\section{Optimization of IAA production by central composite design}

The studied isolates were screened for their ability to produce IAA. Results showed that 77 isolates among the 80 tested ones were able to produce this phytohormone. The isolate I69 leads to the highest IAA production $(135 \mu \mathrm{g} / \mathrm{ml})$. The effects of various factors on IAA production by $\mathrm{I} 69$ and its optimization were studied using a central composite design containing 30 experiments. The experimental design, including the different combinations between studied factors and observed responses for each experiment, is shown in Table 2.

\section{Statistical validation of the postulated model}

Variance analysis shows that the main regression effect is significant since the $p$ value is lower than 0.05 (Table 3). The coefficient of determination $R^{2}$ (93.4\%) was sufficient and gave excellent compatibility between the experimental and predicted values of the postulated model. Figure 3 confirms that the curve of observed values versus predicted ones has a straight line appearance.

\section{Factors effects and fitted model}

Table 4 presents the different estimated coefficients of the studied factors as well as the statistical values of Student's $t$ and the observed probability ( $p$ value). The values of Student's test are used to determine the significance of each parameter, while $p$ values are defined as the lowest level of importance, leading to the rejection of null hypothesis $\mathrm{H}_{0}(\mathrm{bi}=0, \alpha=0.05)$. In general, the greater is the magnitude of $t$, the smaller is the $p$ value, and the larger is the coefficient corresponding term. Regarding those results (Table 4 ), the statistically significant coefficients were as follows:

- The constant $\mathrm{b}_{0}$

- The quadratic terms $b_{11}, b_{22}$.

All these factors have a $p$ value less than 0.05 .

The mathematical model representing the response in terms of significant coefficients is represented by the following equation (Eq. (2)):

$$
\hat{Y}=108-56,39 X_{11}^{2}-93,25 X_{22}^{2}
$$

\section{Optimization of parameters Isoresponses plot}

The isoresponse profile plot (Fig. 4) allowed us to consider various solutions relating to the operating parameters.

According to literature, the maximum production of IAA was reached after 9 days of incubation with a L-Trp concentration of $2 \mathrm{~g} / \mathrm{l}$ [3]. Thus, the objective of our 


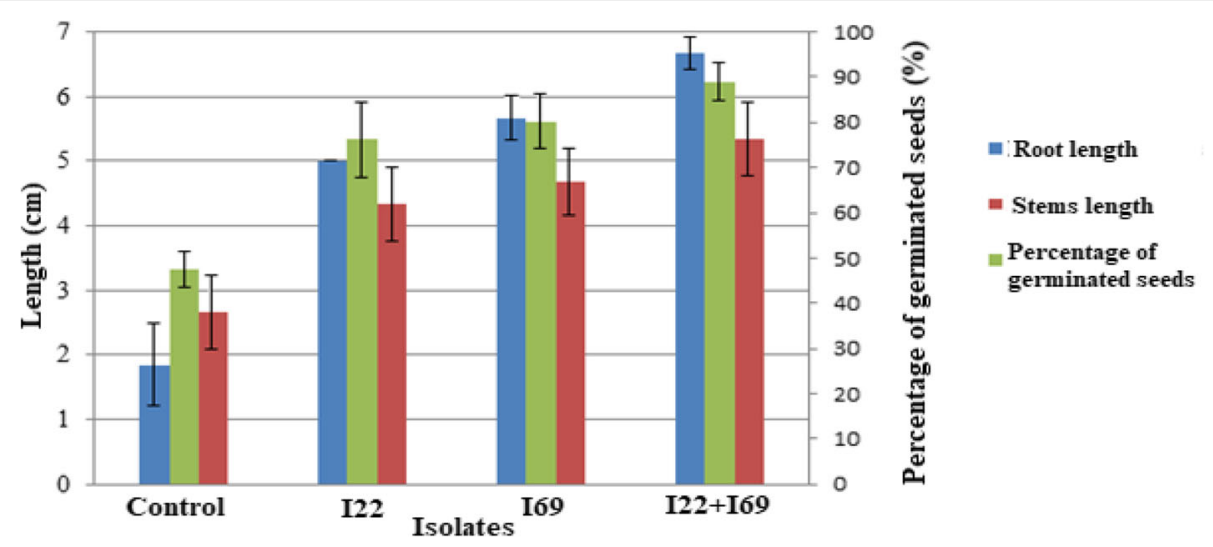

Fig. 2 Inoculation effect by the isolates 122 and 169 on seed germination of Acacia cyanophylla and seedling growth

Table 2 Experimental plan for the optimization of IAA production by the strain 169: experiment 27, 28, 29, and 30 represent central points

\begin{tabular}{|c|c|c|c|c|c|c|}
\hline$N^{\circ} \operatorname{Exp}$ & Incubation temperature $\left({ }^{\circ} \mathrm{C}\right)$ & $\mathrm{pH}$ & {$[\mathrm{NaCl}](\mathrm{g} / \mathrm{l})$} & [Tryptophane] (g/l) & Incubation time (days) & {$[\mathrm{IAA}](\mu \mathrm{g} / \mathrm{ml})$} \\
\hline 1 & 30 & 4.0 & 0.10 & 1 & 15 & 6.90 \\
\hline 2 & 42 & 4.0 & 0.10 & 1 & 1 & 6.34 \\
\hline 3 & 30 & 9.0 & 0.10 & 1 & 1 & 18.87 \\
\hline 4 & 42 & 9.0 & 0.10 & 1 & 15 & 4.91 \\
\hline 5 & 30 & 4.0 & 1.00 & 1 & 1 & 8.25 \\
\hline 6 & 42 & 4.0 & 1.00 & 1 & 15 & 2.76 \\
\hline 7 & 30 & 9.0 & 1.00 & 1 & 15 & 11.34 \\
\hline 8 & 42 & 9.0 & 1.00 & 1 & 1 & 6.58 \\
\hline 9 & 30 & 4.0 & 0.10 & 9 & 1 & 5.00 \\
\hline 10 & 42 & 4.0 & 0.10 & 9 & 15 & 5.80 \\
\hline 11 & 30 & 9.0 & 0.10 & 9 & 15 & 6.96 \\
\hline 12 & 42 & 9.0 & 0.10 & 9 & 1 & 4.03 \\
\hline 13 & 30 & 4.0 & 1.00 & 9 & 15 & 4.30 \\
\hline 14 & 42 & 4.0 & 1.00 & 9 & 1 & 3.76 \\
\hline 15 & 30 & 9.0 & 1.00 & 9 & 1 & 27.84 \\
\hline 16 & 42 & 9.0 & 1.00 & 9 & 15 & 32.41 \\
\hline 17 & 30 & 6.5 & 0.55 & 5 & 8 & 90.72 \\
\hline 18 & 42 & 6.5 & 0.55 & 5 & 8 & 2.55 \\
\hline 19 & 36 & 4.0 & 0.55 & 5 & 8 & 2.98 \\
\hline 20 & 36 & 9.0 & 0.55 & 5 & 8 & 16.58 \\
\hline 21 & 36 & 6.5 & 0.10 & 5 & 8 & 119.73 \\
\hline 22 & 36 & 6.5 & 1.00 & 5 & 8 & 123.27 \\
\hline 23 & 36 & 6.5 & 0.55 & 1 & 8 & 157.79 \\
\hline 24 & 36 & 6.5 & 0.55 & 9 & 8 & 108.14 \\
\hline 25 & 36 & 6.5 & 0.55 & 5 & 1 & 121.93 \\
\hline 26 & 36 & 6.5 & 0.55 & 5 & 15 & 88.92 \\
\hline 27 & 36 & 6.5 & 0.55 & 5 & 8 & 118.19 \\
\hline 28 & 36 & 6.5 & 0.55 & 5 & 8 & 118.27 \\
\hline 29 & 36 & 6.5 & 0.55 & 5 & 8 & 117.66 \\
\hline 30 & 36 & 6.5 & 0.55 & 5 & 8 & 117.55 \\
\hline
\end{tabular}


Table 3 Analysis of variance for the fitted model

\begin{tabular}{llllll}
\hline Source of variance & DF & SS & MS & $F_{\text {ratio }}$ & $p$ value \\
\hline$R$ & 20 & 79056.424 & 3952.82 & 6.3636 & $0.0036^{*}$ \\
$r$ & 9 & 5590.451 & 621.16 & & \\
Total & 29 & 84646.875 & & & \\
$R^{2}$ & $93 \%$ & & & & \\
\hline$R$
\end{tabular}

$R$ regression, $r$ residual, $S S$ sum of squares, DF degrees of freedom, MS mean square, $R^{2}$ coefficient of determination

*Statistically significant at $p<0.05$ probability

study was to optimize the studied parameters to produce the highest amount of IAA by I69 while minimizing incubation time and concentration of L-Trp added to growth medium.

Considering the isoresponse plot (Fig. 4), the minimum incubation time to reach the desired yield $(166 \mu \mathrm{g} /$ $\mathrm{ml}$ ) is 1 day. For this period, $\mathrm{L}-\mathrm{Trp}$ and $\mathrm{NaCl}$ concentrations giving this yield are respectively $1 \mathrm{~g} / \mathrm{l}$ and $0.1 \mathrm{~g} / \mathrm{l}$. The next step is to fix these values for the three previous parameters and look for the values of the two other factors.

The white area in isoresponse plot (Fig. 4) shows a compromise zone for both parameters: incubation temperature and $\mathrm{pH}$ to obtain the desired concentration of IAA by isolate I69 after fixing the other three parameters at their optimal level. The fixation of these parameters (concentration of L-Trp and $\mathrm{NaCl}$ and incubation time) allowed us to know the domains of variation of the other factors: temperature of incubation and $\mathrm{pH}$. Hence, obtaining a concentration of $166 \mu \mathrm{g} \mathrm{IAA} / \mathrm{ml}$ requires an incubation period of 1 day, respective concentrations of L-Trp and $\mathrm{NaCl}$ of $1 \mathrm{~g} / \mathrm{l}$ and $0.1 \mathrm{~g} / \mathrm{l}$, a $\mathrm{pH}$ value between
6.19 and 6.74 , and an incubation temperature between 34.46 and $36.18^{\circ} \mathrm{C}$.

The desirability study allowed us to define precisely the optimized values of the five studied factors.

\section{Desirability study}

This optimization tool allowed us to know precisely the optimal values of studied parameters, leading to the expected yield with a defined degree of compromise (desirability). The desirability plot of optimal IAA production conditions is shown in Fig. 5.

This plot indicates that it is possible to achieve an optimal IAA yield with relative desirability equal to $98 \%$. Thus, parameters giving the best IAA production are an incubation temperature of $36^{\circ} \mathrm{C}$, a $\mathrm{pH}$ of 6.5 , respective L-Trp, $\mathrm{NaCl}$ concentrations of $1 \mathrm{~g} / \mathrm{l}$ and $0.1 \mathrm{~g} / \mathrm{l}$, and an incubation time of 1 day. With these conditions, we have a $98 \%$ probability to produce IAA at a concentration of $166 \mu \mathrm{g} \mathrm{IAA} / \mathrm{ml}$.

\section{Discussion}

The variation in IAA production by different rhizobial isolates and the influence of cultural conditions on IAA produced amount has been reported by many authors [39-41]. The variation in IAA production is may be due to variation in L-Trp utilization by each isolate. Our results revealed that IAA production by the tested isolates was much higher than those found in previous studies. Indeed, the maximal reported production amounts were $80.96 \mu \mathrm{g} I A A / m l$, $99.7 \mu \mathrm{g} \mathrm{AIA} / \mathrm{ml}, 107 \mu \mathrm{g} \mathrm{IAA} / \mathrm{ml}$, and $142 \mu \mathrm{g} \mathrm{IAA} / \mathrm{ml}$ by Rhizobium sp. isolated respectively from root nodules of

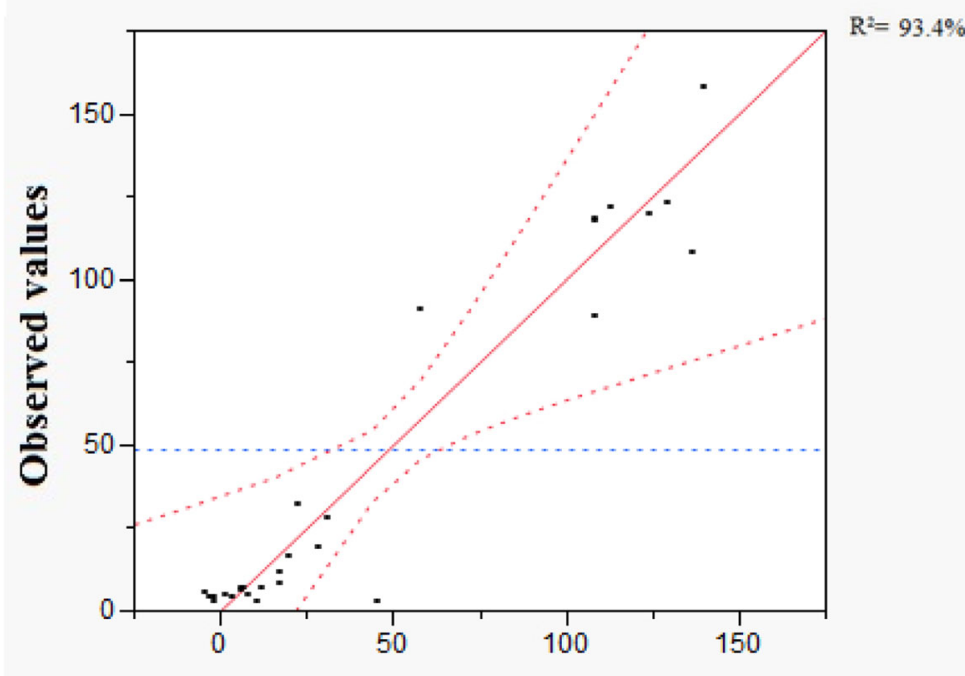

Predicted values

Fig. 3 Curve of observed values in term of predicted ones 
Table 4 Effects of model coefficients that relate the response to factors

\begin{tabular}{|c|c|c|c|c|c|}
\hline Term & Coefficient & Estimation & Erreur standard & Report $\boldsymbol{t}$ & Prob.> $|\boldsymbol{t}|$ \\
\hline Constant & $b_{0}$ & 107.99474 & 7.786987 & 13.87 & $<0.0001^{* * *}$ \\
\hline Incubation temperature $(30,42)$ & $b_{1}$ & -6.168889 & 5.874433 & -1.05 & 0.321 \\
\hline $\mathrm{pH}(4,9)$ & $b_{2}$ & 4.635 & 5.874433 & 0.79 & 0.4504 \\
\hline$[\mathrm{NaCl}](0,1,1)$ & $b_{3}$ & 2.3316667 & 5.874433 & 0.4 & 0.7007 \\
\hline [Tryptophane](1,9) & $b_{4}$ & -1.416667 & 5.874433 & -0.24 & 0.8148 \\
\hline Incubation time $(1,15)$ & $b_{5}$ & -2.127778 & 5.874433 & -0.36 & 0.7256 \\
\hline Incubation temperature ${ }^{*} \mathrm{pH}$ & $b_{12}$ & -0.705625 & 6.230777 & -0.11 & 0.9123 \\
\hline Incubation temperature ${ }^{*}[\mathrm{NaCl}]$ & $b_{13}$ & 0.651875 & 6.230777 & 0.1 & 0.919 \\
\hline $\mathrm{pH}^{*}[\mathrm{NaCl}]$ & $b_{23}$ & 3.023125 & 6.230777 & 0.49 & 0.6391 \\
\hline Incubation temperature * $[$ Tryptophane $]$ & $b_{14}$ & 1.666875 & 6.230777 & 0.27 & 0.7951 \\
\hline $\mathrm{pH}^{*}[$ Tryptophane $]$ & $b_{24}$ & 2.183125 & 6.230777 & 0.35 & 0.7341 \\
\hline$[\mathrm{NaCl}]^{*}[$ Tryptophane $]$ & $b_{34}$ & 3.413125 & 6.230777 & 0.55 & 0.5972 \\
\hline Incubation temperature *Incubation time & $b_{15}$ & 3.476875 & 6.230777 & 0.56 & 0.5904 \\
\hline $\mathrm{pH}^{*}$ Incubation time & $b_{25}$ & 0.118125 & 6.230777 & 0.02 & 0.9853 \\
\hline$[\mathrm{NaCl}]^{*}$ Incubation time & $b_{35}$ & 0.878125 & 6.230777 & 0.14 & 0.891 \\
\hline [Tryptophane]*Incubation time & $b_{45}$ & 1.435625 & 6.230777 & 0.23 & 0.8229 \\
\hline Incubation temperature ${ }^{*}$ Incubation temperature & $b_{11}$ & -56.39836 & 15.90287 & -3.55 & $0.0063^{* *}$ \\
\hline $\mathrm{pH}^{*} \mathrm{pH}$ & $b_{22}$ & -93.25336 & 15.90287 & -5.86 & $0.0002^{* * *}$ \\
\hline$[\mathrm{NaCl}]^{*}[\mathrm{NaCl}]$ & $b_{33}$ & 18.466643 & 15.90287 & 1.16 & 0.2754 \\
\hline [Tryptophane]* [Tryptophane] & $b_{44}$ & 29.931643 & 15.90287 & 1.88 & 0.0925 \\
\hline Incubation time ${ }^{*}$ Incubation time & $b_{55}$ & 2.3916429 & 15.90287 & 0.15 & 0.8838 \\
\hline
\end{tabular}

**Statistically significant at $p<0.01$ probability

***Statistically significant at $p<0.001$ probability

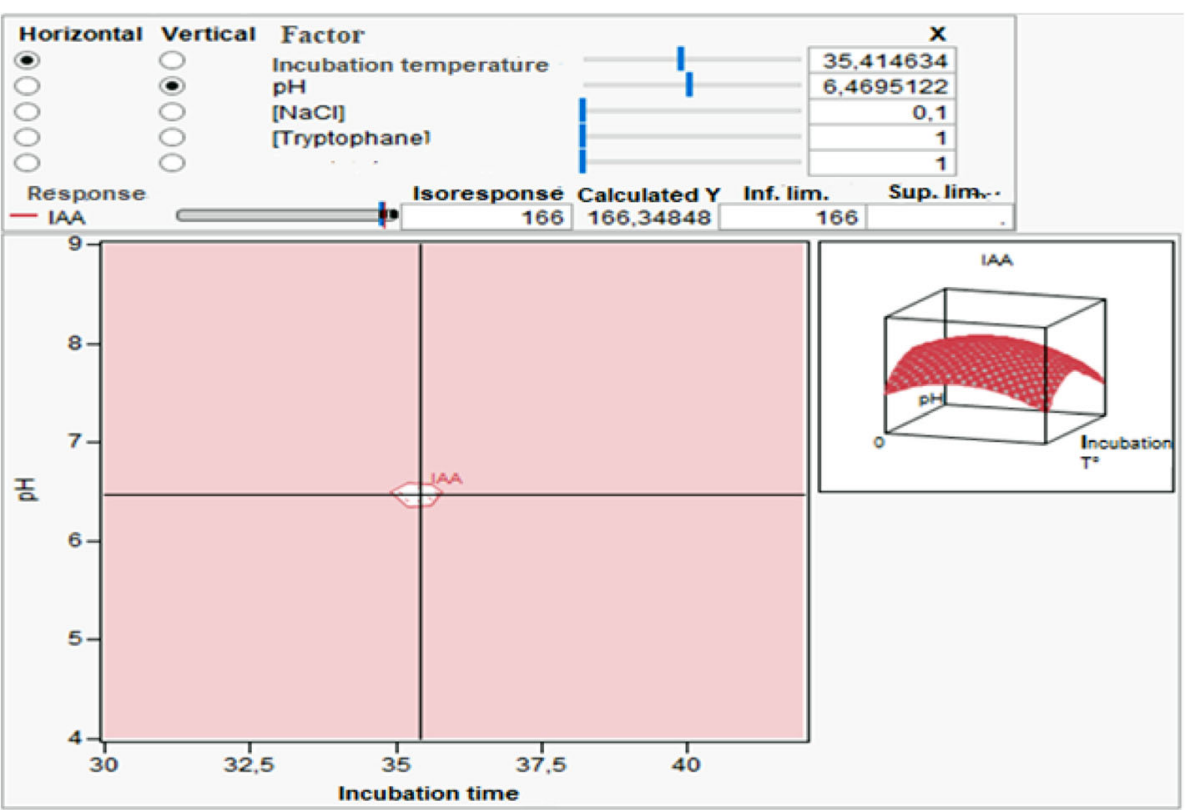

Fig. 4 Isoresponses plot for the IAA production optimization by considering both incubation temperature and pH factors and by fixing the concentrations of L-Trp at $1 \mathrm{~g} / \mathrm{l}$ and $\mathrm{NaCl}$ at $0.1 \mathrm{~g} / \mathrm{l}$ and the incubation time at 1 day 


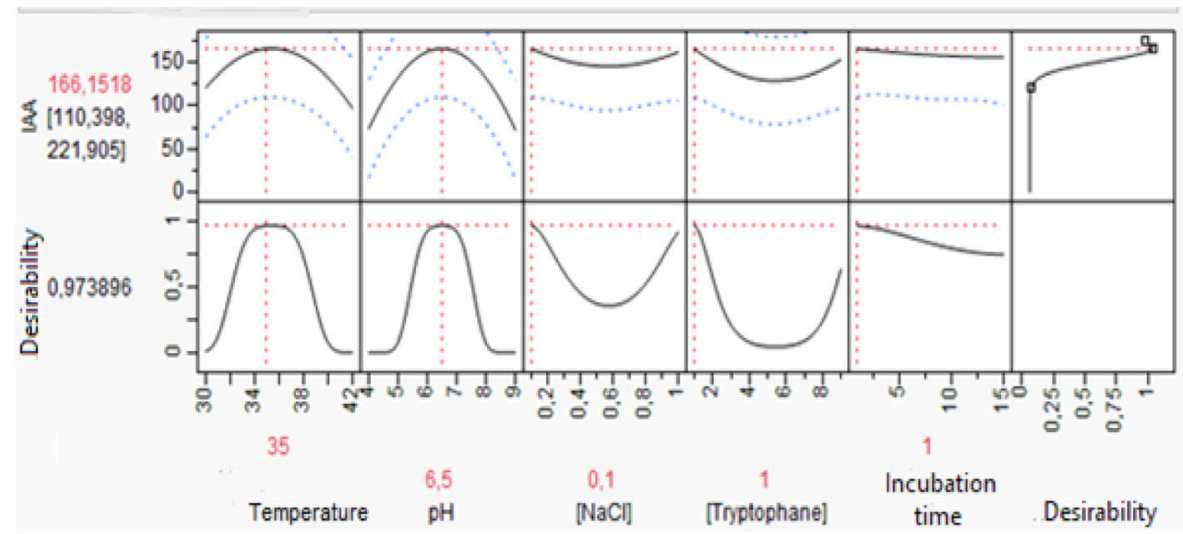

Fig. 5 Desirability plot showing the precise operating conditions leading to the optimal yield of IAA production

Vigna trilobata (L) Verdc., Cajanus cajan, Alysicarpus vaginalis DC, and Phaseolus mungo [42-45].

The IAA production by a combination of Rhizobium, Agrobacterium, and Paenibacillus was studied by Shokri and Emtiazi [28]. These researchers found an increase in IAA concentration produced by Rhizobium and Paenibacillus combination, showing a synergistic effect. But this concentration decreased when Agrobacterium was used in combination with the other two bacteria. Similar results were obtained by El-Shanshoury [46], who found that double inoculation with Azotobacter chroococcum and Azospirillum brasilense or Streptomyces mutabilisa significantly stimulated IAA production.

The reduction in IAA production can be due to the release of enzymes degrading this hormone, such as IAA oxidase and peroxidase, as already reported by several authors [28, 43, 47]. Other studies have reported the ability of rhizobia to produce these enzymes in the medium inducing reduction of hormone concentration $[43,48]$. Incompatibility of I75 with I22 and I69 may be due to competition between these bacterial strains and to production of some compounds inhibiting bacterial growth. This antagonistic effect was previously explained by nutritive competition phenomena when bacterial density is high $[49,50]$.

Our results concerning the effect of inoculation by the tested bacteria on Acacia cyanophylla seed germination are consistent with several studies [26, 41, 44] which claimed that the use of PGPR specifically IAA producing bacteria might have a significant effect on increasing seed germination rate and promoting plant growth.

It was shown that longer root systems provide better access to stored water and nutrients such as nitrogen, a soluble nutrient that tends to seep into the deeper soil layers [51]. IAA controls a wide variety of processes in plant growth and root system development. Indeed, low concentrations of IAA can stimulate primary root elongation, while higher levels of this hormone stimulate lateral root formation, decrease primary root length, and increase absorbent hair formation [52]. Seed germination in any plant species is an active metabolic process that begins when seeds are exposed to an appropriate temperature and humidity [53]. IAA has been known for its participation in the early stages of germination in certain plant seedlings [54]. The synthesis of plant growth regulators, in particular IAA, initiates germination of the plants' seeds, but initiation is triggered by germination stimulators released from host plant roots [53].

The experimental design was a powerful tool that has been used successfully to test the relative importance of environmental factors in IAA production. Shokri and Emtiazi [28] revealed a maximum IAA production by Rhizobium sp. at a concentration of 3 $\mathrm{g} / \mathrm{l}$ of L-Trp after 3 days of incubation at $30^{\circ} \mathrm{C}$. A similar study by Leong [55] mentioned that the optimal amount of IAA produced by Rhodopseudomonas palutris was obtained after 2 days of incubation at $35{ }^{\circ} \mathrm{C}$ in the presence of $5 \mathrm{~g} / \mathrm{l} \mathrm{L}$-Trp. Similarly, Ghosh and Basu [56] showed that Rhizobium spp. isolated from root nodules of Dalbergia lanceolaria produced a maximum amount of IAA at a concentration of 2.5 g/l L-Trp. The use of experimental design allowed us to obtain the highest yield of IAA by the strain I69, which was higher than that obtained by the combination of this bacterial isolate with another one (I22 + I69). Otherwise, a better result compared to previous studies concerning incubation time and L-Trp concentration (1 day of incubation and L-Trp concentration of $1 \mathrm{~g} / \mathrm{l}$ ) was detected. Moreover, the incubation temperature obtained by the used central composite design $\left(36^{\circ} \mathrm{C}\right)$ was close to that obtained by Leong [55]. The predictive response generated by the validated model under optimal parameters and the real obtained yield under these conditions were so close. We can, therefore, conclude that the precision of this approach has been well checked. 


\section{Conclusion}

Indole-3-acetic acid is one of the main physiological active hormones controlling various important processes in plants. In this study, bacterial isolates were screened in order to determine their ability for IAA production. Then, the inoculation effect by isolates in pure culture or in combination with Acacia cyanophylla seed's germination was studied using the best performing isolates in terms of IAA production. The optimization of this phytohormone's production was evaluated using a response surface methodology based on the central composite design on five factors. This method allowed us to determine the optimal conditions necessary to obtain the best IAA production $(166 \mu \mathrm{g} / \mathrm{ml})$. This yield, which exceeds that obtained by the synergy between the best strains producing IAA, has been experimentally verified. Finally, this study has shown that experimental designs provide a fast and relevant approach that can be used for optimizing the production of other phytohormones obtained from different strains.

\section{Abbreviations}

$\mathrm{FeCl}_{3}$ : Iron trichloride; $\mathrm{H}_{2} \mathrm{SO}_{4}$ : Sulfuric acid; $\mathrm{HClO}_{4}$ : Perchloric acid; $\mathrm{HgCl}$ 2: Mercury Chloride; IAA: Indole-3-Acetic Acid; $\mathrm{MgSO}_{4}$

$7 \mathrm{H}_{2} \mathrm{O}$ : Magnesium sulfate heptahydrate; $\mathrm{NaCl}$ : Sodium chloride; PGPR: Plant Growth Promoting Rhizobacteria; pH: Potential hydrogen; RPM: Rotation per minute; Trp: Tryptophan; YMA: Yeast-Mannitol-Agar; a: Alpha

\section{Acknowledgements}

The authors are thankful to the scientific support of Microbial Biotechnology Laboratory and the "Centre Universitaire d'Interface" SMBA University, Fez, Morocco.

\section{Authors' contributions}

LS conducted the main experiments, designed the work, and wrote the manuscript. FM analyzed the data and contributed to the part of experimental designs. CM participated in some experiments. FBK directed the work. All authors read and approved the final manuscript.

\section{Funding}

This work did not receive funding from any organization or institution.

\section{Availability of data and materials}

All data generated or analyzed during this study are included in this published article

\section{Ethics approval and consent to participate}

Not applicable.

\section{Consent for publication}

Not applicable.

\section{Competing interests}

The authors declare that they have no competing interests.

\section{Author details}

'Laboratory of Microbial Biotechnology, Sciences and Technology Faculty, Sidi Mohamed Ben Abdellah University, P.O. Box 2202, Fez, Morocco. ${ }^{2}$ Physico-chemical laboratory of inorganic and organic materials, Materials Science Center (MSC), Ecole Normale Supérieure, Mohammed V University in Rabat, Rabat, Morocco.
Received: 12 October 2019 Accepted: 4 June 2020

Published online: 18 June 2020

\section{References}

1. Khan MS, Zaidi A, Ahmad E (2014) Mechanism of phosphate solubilization and physiological functions of phosphate-solubilizing microorganisms. Khan M., Zaidi A., Musarrat J. Phosphate solubilizing microorg. Springer, Cham, p. 31-62. doi:https://doi.org/10.1007/978-3-319-08216-5_2.

2. Damam M, Kaloori K, Gaddam B, Kausar R (2016) Plant growth promoting substances (phytohormones) produced by rhizobacterial strains isolated from the rhizosphere of medicinal plants. Int J Pharm Sci Rev Res 37(1):130-136

3. Chaiharn M, Lumyong S (2011) Screening and optimization of indole-3acetic acid production and phosphate solubilization from rhizobacteria aimed at improving plant growth. Curr Microbiol 62(1):173-181. https://doi. org/10.1007/s00284-010-9674-6

4. Ryu RJ, Patten CL (2008) Aromatic amino acid-dependent expression of indole-3-pyruvate decarboxylase is regulated by tyrr in Enterobacter cloacae UW5. J Bacteriol 190(21):7200-7208. https://doi.org/10.1128/JB.00804-08

5. Ali B (2015) Bacterial auxin signaling: comparative study of growth induction in Arabidopsis thaliana and Triticum aestivum. Turk J Botany 39(1):1-9

6. Granada CE, Strochein M, Vargas LK, Bruxel M, Sá ELSD, Passaglia LM (2014) Genetic diversity and symbiotic compatibility among rhizobial strains and Desmodium incanum and Lotus spp. plants. Genet Mol Biol 37(2):396-405

7. Sziderics AH, Rasche F, Trognitz F, Sessitsch AWE (2007) Bacterial endophytes contribute to abiotic stress adaptation in pepper plants (Capsicum annuum L.). Can J Microbiol 53(11):1195-1202. https://doi.org/10. 1139/W07-082

8. Singh J, Singh P, Ray S, Rajput RS, Singh HB (2019) Plant growthpromoting rhizobacteria: benign and useful substitute for mitigation of biotic and abiotic stresses. Plant Growth Promot. Rhizobacteria Sustain. Stress Manag. Springer, Singapore, p. 81-101. doi:https://doi.org/10. 1007/978-981-13-6536-2_5.

9. Wani S, Kumar V, Shriram V, Sah S (2016) Phytohormones and their metabolic engineering for abiotic stress tolerance in crop plants. Crop J 4(3):162-176

10. Upreti KK, Sharma M (2016) Role of plant growth regulators in abiotic stress tolerance. In: Rao N, Shivashankara K, Laxman R (eds) Abiotic stress physiology of horticultural crops. Springer, New Delhi, pp 19-46. https://doi. org/10.1007/978-81-322-2725-0_2

11. Iabal N, Umar S, Khan N, Khan M (2014) A new perspective of phytohormones in salinity tolerance: regulation of proline metabolism. Environ Exp Bot 100:34-42

12. Fahad S, Hussain S, Bano A, Saud S, Hassan S, Shan D et al (2015) Potential role of phytohormones and plant growth-promoting rhizobacteria in abiotic stresses: consequences for changing environment. Environ Sci Pollut Res 22: 4907-4921. https://doi.org/10.1007/s11356-014-3754-2

13. Sheng X, Xia J (2006) Improvement of rape (Brassica napus) plant growth and cadmium uptake by cadmium-resistant bacteria. Chemosphere 64(6): 1036-1042

14. Aeron A, Kumar S, Pandey P, Maheshwari DK (2011) Emerging role of plant growth promoting rhizobacteria in agrobiology. Bact. Agrobiol. Crop Ecosyst. Springer, Berlin, Heidelberg, p. 1-36. doi:https://doi.org/10.1007/9783-642-18357-7 1.

15. Ramos Solano B, Barriuso Maicas J, Pereyra de la Iglesia MT, Domenech J, Gutiérrez Mañero FJ (2008) Systemic disease protection elicited by plant growth promoting rhizobacteria strains: relationship between metabolic responses, systemic disease protection, and biotic elicitors. Phytopathology 98(4):451-457. https://doi.org/10.1094/phyto-98-4-0451

16. Gutiérrez-Mañero FJ, Ramos-Solano B, Probanza A, Mehouachi J, Tadeo FR, Talon M (2001) The plant-growth-promoting rhizobacteria Bacillus pumilus and Bacillus licheniformis produce high amounts of physiologically active gibberellins. Physiol Plant 111(2):206-211. https://doi.org/10.1034/j.13993054.2001.1110211.x

17. Raheem A, Shaposhnikov A, Belimov AA, Dodd IC, Ali B (2018) Auxin production by rhizobacteria was associated with improved yield of wheat (Triticum aestivum L.) under drought stress. Arch Agron Soil Sci 64(4):574587. https://doi.org/10.1080/03650340.2017.1362105

18. Belimov AA, Puhalsky IV, Safronova VI, Shaposhnikov Al, Vishnyakova MA Semenova EV et al (2015) Role of plant genotype and soil conditions in 
symbiotic plant-microbe interactions for adaptation of plants to cadmiumpolluted soils. Water Air Soil Pollut 226(8):264. https://doi.org/10.1007/ s11270-015-2537-9

19. Theunis M, Prinsen E, Kobayashi H, Broughton WJ (2004) Flavonoids, NodD1, NodD2, and nod-box NB15 modulate expression of the y4wEFG locus that is required for indole-3-acetic acid synthesis in Rhizobium sp. strain NGR234. Mol Plant-Microbe Interact 17(10):1153-1161. https://doi.org/10.1094/MPMI. 2004.17.10.1153

20. Ghosh S, Basu PS (2006) Production and metabolism of indole acetic acid in roots and root nodules of Phaseolus mungo. Microbiol Res 161(4):362-366

21. Spaepen S, Vanderleyden J, Okon Y (2009) Plant growth-promoting actions of rhizobacteria. Adv Bot Res 51:283-320

22. Zerrouk IZ, Rahmoune B, Khelifi L, Mounir K, Baluska F, Ludwig-Müller (2019) Algerian Sahara PGPR confers maize root tolerance to salt and aluminum toxicity via ACC deaminase and IAA. Acta Physiol Plant 41(6):91. https://doi.org/10.1007/s11738-019-2881-2

23. Chandra S, Askari K, Kumari M (2018) Optimization of indole acetic acid production by isolated bacteria from Stevia rebaudiana rhizosphere and its effects on plant growth. J Genet Eng Biotechnol 16:581-586. https://doi.org/ 10.1016/j.jgeb.2018.09.001

24. Shoukry AA, El-Sebaay HH, El-Ghomary AE (2018) Assessment of indole acetic acid production from rhizobium leguminosarum strains. Curr Sci Int 7:60-69

25. Fadil M, Farah A, Ben SM, Rachiq S (2015) Optimisation des paramètres influençant I'hydrodistillation de Rosmarinus officinalis $L$. par la méthodologie de surface de réponse optimization of parameters influencing the hydrodistillation of Rosmarinus officinalis $L$. by response surface methodology. J Mater Environ Sci 6(8):2346-2357

26. Apine OA, Jadhav JP (2011) Optimization of medium for indole-3-acetic acid production using Pantoea agglomerans strain PVM. J Appl Microbiol 110(5): 1235-1244. https://doi.org/10.1111/j.1365-2672.2011.04976x

27. Harikrishnan H, Shanmugaiah V, Balasubramanian N (2014) Optimization for production of indole acetic acid (IAA) by plant growth promoting Streptomyces sp VSMGT1014 isolated from rice rhizosphere. Int J Curr Microbiol Appl Sci 3(8):158-171

28. Shokri D, Emtiazi G (2010) Indole-3-acetic acid (IAA) production in symbiotic and non-symbiotic nitrogen-fixing bacteria and its optimization by taguchi design. Curr Microbiol 61(3):217-225. https://doi.org/10.1007/s00284-010-9600-y

29. Sasirekha B, Shivakumar S (2012) Statistical optimization for improved indole-3-acetic acid (iaa) production by Pseudomonas aeruginosa and demonstration of enhanced plant growth. J Soil Sci Plant Nutr 12(4): 863-873

30. Vincent JM (1970) A manual for the practical study of the root-nodule bacteria. IBP Handb 15Blackwell Sci Publ Oxford.

31. Beck D, Materon L, (1993) Practical Rhizobium-legume technology manual. Practical Rhizobium-legume technology manual., vol(19).

32. Berrada H, Nouioui I, Houssaini M, Ghachtouli N, Gtari M, Fikri Benbrahim K (2012) Phenotypic and genotypic characterizations of rhizobia isolated from root nodules of multiple legume species native of fez, Morocco. African J Microbiol Res 6(25):5314-5324

33. Bric JM, Bostock RM, Silverstonet SE (1991) Rapid in situ assay for indoleacetic acid production by bacteria immobilized on a nitrocellulose membrane. Appl Environ Microbiol 57(2):535-538

34. Dhabhai K, Batra A (2010) Hormonal regulation impact on regeneration of Acacia nilotica L. a nitrogen fixing tree. World Appl Sci J 11(9):1148-1153

35. Gantait S, Kundu S, Das P (2018) Acacia: an exclusive survey on in vitro propagation. J Saudi Soc Agric Sci 17(2):163-177

36. Satrani B, El Ouadihi N, Guedira A, Frey-Klett P, Arahou M, Garbaye J (2009) Effet de la bactérisation des graines Sur la croissance des plants de Cedrus atlantica Manetti. Biotechnol Agron Société Environ 13(3):367-372

37. Reddy MS, Rahe JE, Levesque CA (1992) Influence of onion seed bacterization on germination and mycosphere microflora of Sclerotium cepivorum sclerotia. Can J Microbiol 38(11):1135-1143. https://doi.org/10. $1139 / \mathrm{m} 92-186$

38. Fadil M, Fikri-Benbrahim K, Rachiq S, Ihssane B, Lebrazi S, Chraibi M et al (2018) Combined treatment of Thymus vulgaris L., Rosmarinus officinalis $L$ and Myrtus communis L. essential oils against Salmonella typhimurium: optimization of antibacterial activity by mixture design methodology. Eur Pharm Biopharm 126:211-220. https://doi.org/10.1016/j.ejpb.2017.06.002

39. Rejili M, Mahdhi M, Ferchichi A, Mars M (2009) Natural nodulation of five wild legumes in the south of Tunisia. Plant Biosyst 143:34-39. https://doi. org/10.1080/11263500802633238
40. Vasconcellos R, Silva M, Ribeiro C, Cardoso E (2010) Isolation and screening for plant growth-promoting (PGP) actinobacteria from Araucaria angustifolia rhizosphere soil. Sci Agric 67(6):743-746

41. Bhargava Y, Murthy JSR, Kumar TVR, Rao MN (2016) Phenotypic, stress tolerance and plant growth promoting characteristics of rhizobial isolates from selected wild legumes of semiarid region, Tirupati, India. Adv Microbiol 6(1):1-12. https://doi.org/10.4236/aim.2016.61001

42. Bhattacharyya R, Pati B (2000) Growth behaviour and indole acetic acid (IAA) production by a rhizobium isolated from root nodules of Alysicarpus vaginalis DC. Acta Microbiol Immunol Hung 47(1):41-51

43. Datta C, Basu P (2000) Indole acetic acid production by a rhizobium species from root nodules of a leguminous shrub, Cajanus cajan. Microbiol Res 155(2):123-127

44. Ghosh S, Sengupta C, Maiti TK, Basu PS (2008) Production of 3-indolylacetic acid in root nodules and culture by a rhizobium species isolated from root nodules of the leguminous pulse Phaseolus mungo. Folia Microbiol (Praha) 53(4): p 351. https://doi.org/10.1007/s12223-008-0054-6

45. Kumar P, Ram M (2012) Production of indole acetic acid by rhizobium isolates from Vigna trilobata (L) Verdc. African J Microbiol Res 6(27):55365541

46. El-Shanshoury AR (1995) Interactions of Azotobacter chroococcum, Azospirillum brasilense and Streptomyces mutabilis, in relation to their effect on wheat development. J Agron Crop Sci 175(2):119-127. https://doi.org/10. 1111/j.1439-037X.1995.tb01137.x

47. Arora PK, Sharma A, Bae H (2015) Microbial degradation of indole and its derivatives. J Chem 2015:13. https://doi.org/10.1155/2015/129159

48. Shende R, Patil M (2011) Growth behaviour and indole acetic acid (IAA) production by a Rhizobium sp. isolated from Cajanus cajan plant. Int J Pharma Bio Sci 2(4):621-628

49. Hozzein WN, Rabie W, Ali MIA (2011) Screening the Egyptian desert actinomycetes as candidates for new antimicrobial compounds and identification of a new desert Streptomyces strain. African J Biotechnol 10(12):2295-2301. https://doi.org/10.5897/AJB10.1973

50. Santiago CD, Yagi S, ljiMa M, NashiMoto T, SawaDa M, IkeDa S et al (2017) Bacterial compatibility in combined inoculations enhances the growth of potato seedlings. Microbes Environ 32(1):14-23. https://doi.org/10.1264/ jsme2.ME16127

51. Judd LA, Jackson BE, Fonteno WC (2015) Advancements in root growth measurement technologies and observation capabilities for containergrown plants. Plants 4(3):369-392. https://doi.org/10.3390/plants4030369

52. Vacheron J, Desbrosses $G$, Bouffaud $M-L$, Touraine B, Moënne-Loccoz $Y$, Muller D et al (2013) Plant growth-promoting rhizobacteria and root system functioning. Front Plant Sci 4:356. https://doi.org/10.3389/fpls.2013.00356

53. Slavov S, Van Onckelen H, Batchvarova R, Atanassov A, Prinsen E (2004) IAA production during germination of Orobanche spp. seeds. J Plant Physiol 161(7):847-853

54. Ljung K, Anders O, Lioussanne L, Sandberg G (2001) Developmental regulation of indole-3-acetic acid turnover in scots pine seedlings. Plant Physiol 125(1):464-475

55. Leong PP (2015) Production and optimization of Indole-3-acetic acid by Rhodopseudomonas Palutris. Universiti Teknologi Malaysia

56. Ghosh A, Basu P (2002) Growth behaviour and bioproduction of indole acetic acid by a rhizobium sp. isolated from root nodules of a leguminous tree Dalbergia lanceolaria. Indian J Exp Biol 40(7):796-801

\section{Publisher's Note}

Springer Nature remains neutral with regard to jurisdictional claims in published maps and institutional affiliations. 